\title{
Qualidade fisiológica de sementes crioulas de milho e feijão de pequenos agricultores de Ituiutaba-MG
}

\author{
Physiological quality of native seeds of corn and beans from small farmers in Ituiutaba-MG \\ Calidad fisiológica de las semillas nativas de maíz y frijol de los pequeños agricultores de Ituiutaba- \\ MG
}

Recebido: 21/09/2021 | Revisado: 29/09/2021 | Aceito: 02/10/2021 | Publicado: 04/10/2021

\author{
Cleverson Matias dos Santos \\ ORCID: https://orcid.org/0000-0002-2487-0380 \\ Universidade do Estado de Minas Gerais, Brasil \\ E-mail: cleversonmds20@gmail.com \\ Bruno de Moraes Nunes \\ ORCID: https://orcid.org/0000-0002-5629-1287 \\ Universidade do Estado de Minas Gerais, Brasil \\ E-mail: bruno.nunes@uemg.br \\ Josef Gastl Filho \\ ORCID: https://orcid.org/0000-0003-3492-1089 \\ Universidade Federal de Uberlândia, Brasil \\ E-mail: josef.gastl@ufu.br \\ Anderson Aparecido da Silva \\ ORCID: https://orcid.org/0000-0002-9926-2873 \\ Universidade do Estado de Minas Gerais, Brasil \\ E-mail: meg20211979@gmail.com
}

\begin{abstract}
Resumo
O milho (Zea mays L.) e o feijão-comum (Phaseolus vulgaris L.) despertam grande interesse agrícola no Brasil e no mundo, o feijão-caupi (Vigna unguiculata (L.) Walp.) e feijão-fava (Phaseolus lunatus L.) adaptaram-se perfeitamente ao clima do Norte/Nordeste brasileiro. Objetivou-se nesse trabalho avaliar a qualidade física e fisiológica de sementes crioulas de milho e feijão de pequenos agricultores em Ituiutaba-MG. O delineamento experimental foi o inteiramente casualizado, com 6 variedades e 4 repetições de 50 sementes. As avaliações ocorreram do $4^{\circ}$ ao $7^{\circ}$ dia para o milho, $5^{\circ}$ ao $8^{\circ}$ dia para feijão-caupi e $5^{\circ}$ ao $9^{\circ}$ dia para feijão-comum e feijão-fava, seguindo as Regras para Análises de Sementes. Foram analisados: Peso de Mil Sementes, Índice de Velocidade de Emergência, Índice de Velocidade de Germinação, Percentual de Germinação, Primeira Contagem de Germinação, Comprimento de Plântulas, Retenção em Peneiras, Biomassa Fresca, Biomassa Seca e Condutividade elétrica. Os resultados foram submetidos à análise de variância pelo teste de Tukey a 5\% de probabilidade de erro. As variedades diferiram-se estatisticamente para PMS, o feijão-fava apresentou maior PMS. Para RP, não observou-se diferenças estatísticas. O milho urbano e o feijão comercial destacaram-se para: IVE e \%G. As variedades de milho rural e urbano não diferiram estatisticamente para PCG, IVG e \%G; o feijão-caupi e feijão comercial destacaram-se para: PCG, IVG e \%G. As variedades de milho não diferiram estatisticamente para: CP, BS e CE. O feijão-fava apresentou menor média de CP; feijão-caupi e feijão comercial destacaram-se para BF. O feijão-caupi apresentou menor vigor para CE.
\end{abstract}

Palavras-chave: Variedades tradicionais; Parâmetros fisiológicos; Emergência; Vigor.

\begin{abstract}
Corn (Zea mays L.) and common bean (Phaseolus vulgaris L.) arouse great agricultural interest in Brazil and worldwide, cowpea (Vigna unguiculata (L.) Walp.) and cowpea (Phaseolus lunatus L.) have adapted perfectly to the climate of the North/Northeast of Brazil. The objective of this work was to evaluate the physical and physiological quality of native corn and bean seeds from small farmers in Ituiutaba-MG. The experimental design was entirely randomized, with 6 varieties and 4 repetitions of 50 seeds. The evaluations occurred from the 4th to the 7th day for corn, 5th to the 8th day for cowpea and 5th to the 9th day for cowpea and cowpea, following the Rules for Seed Analysis. The following were analyzed: Thousand Seed Weight, Emergence Speed Index, Germination Speed Index, Germination Percentage, First Germination Count, Seedling Length, Sieve Retention, Fresh Biomass, Dry Biomass and Electrical Conductivity. The results were submitted to analysis of variance by Tukey's test at 5\% probability of error. The varieties differed statistically for SMP, the cowpea showed higher SMP. For PR, no statistical differences were observed. Urban corn and commercial bean stood out for: EVI and \%G. Rural and urban corn varieties did not differ statistically for PCG, IVG and \%G; cowpea and commercial bean stood out for: PCG, IVG and \%G. Corn
\end{abstract}


varieties did not differ statistically for: CP, BS and CE. Cowpea presented the lowest mean for CP; cowpea and cowpea stand out for BF. The cowpea presented lower vigor for CE.

Keywords: Traditional varieties; Physiological parameters; Emergence; Vigor.

\section{Resumen}

El maíz (Zea mays L.) y el frijol común (Phaseolus vulgaris L.) despiertan un gran interés agrícola en Brasil y en todo el mundo, mientras que el caupí (Vigna unguiculata (L.) Walp.) y el frijol de vaca (Phaseolus lunatus L.) se han adaptado perfectamente al clima del Norte/Nordeste de Brasil. El objetivo de este trabajo fue evaluar la calidad física y fisiológica de semillas nativas de maíz y frijol provenientes de pequeños agricultores de Ituiutaba-MG. El diseño experimental fue totalmente aleatorio, con 6 variedades y 4 repeticiones de 50 semillas. Las evaluaciones se realizaron del $4^{\circ}$ al $7^{\circ}$ día para el maíz, del $5^{\circ}$ al $8^{\circ}$ día para el caupí y del $5^{\circ}$ al $9^{\circ}$ día para el caupí y el caupí, siguiendo las normas de análisis de semillas. Se analizó el peso de mil semillas, el índice de velocidad de emergencia, el índice de velocidad de germinación, el porcentaje de germinación, el recuento de la primera germinación, la longitud de las plántulas, la retención en el tamiz, la biomasa fresca, la biomasa seca y la conductividad eléctrica. Los resultados se sometieron a un análisis de la varianza mediante la prueba de Tukey con una probabilidad de error del 5\%. Las variedades se diferenciaron estadísticamente por la SMP, el caupí mostró una mayor SMP. En cuanto a la RP, no se observaron diferencias estadísticas. El maíz urbano y el caupí destacaron por: EVI y \%G. Las variedades de maíz rural y urbano no difirieron estadísticamente en cuanto a PCG, IVG y \%G; el caupí y la judía comercial destacaron por: PCG, IVG y \%G. Las variedades de maíz no difirieron estadísticamente para: CP, BS y CE. El caupí presentó una media más baja para la PC; el caupí y la caupí destacan para la FB. El caupí mostró menos vigor para la CE.

Palabras clave: Variedades tradicionales; Parámetros fisiológicos; Emergencia; Vigor.

\section{Introdução}

O milho (Zea mays L.) é um dos cereais de maior importância para o Brasil, e é produzido nas diferentes regiões do país. Na região sudeste, considerando-se a produção total, Minas Gerais ganha destaque, sendo o maior produtor com 8,821 milhões de toneladas na projeção da safra 2020/2021 com aumento de 17,2\% em relação à safra 2019/2020, seguido por São Paulo, responsável por 4,560 milhões de toneladas na projeção da safra de 2020/21 (Conab, 2021). Respectivo à produção mundial de milho, o Brasil segue como o $3^{\circ}$ maior produtor com produção de 101 milhões de toneladas (safra 2019/20) atrás somente dos Estados Unidos e China, responsáveis pela produção de 352 e 254 milhões de toneladas de milho, respectivamente (Conab, 2020).

O feijão comum (Phaseolus vulgaris L.) é cultivado no mundo todo, sendo esta a principal espécie cultivada no Brasil, apresentando-se como fundamental para a subsistência humana (Schafranski, 2019). O feijão-fava (Phaseolus lunatus L.) e feijão-caupi (Vigna unguiculata (L.) Walp.) são as espécies que mais se adaptaram ao clima e solo do semiárido brasileiro, além de ter grande importância nutricional e alimentar em pequenas propriedades rurais (Almeida et al., 2020).

A produção de feijão total ( $1^{\mathrm{a}}, 2^{\mathrm{a}}$ e $3^{\mathrm{a}}$ safra) de acordo com a Conab (2021) foi de 3,288 milhões de toneladas na safra 2020/2021, com variação de 2\% em relação à safra 2019/2020; a região Sul apresentou maior produção (934,1 mil toneladas) quando comparada a região Nordeste que na safra 2019/2020 era a maior produtora, passando para o segundo lugar na safra 2020/2021 com 725,4 mil toneladas, ou seja, com queda de 15,6\% em relação à safra anterior (Conab, 2021). Considerando a produção total de feijão-caupi na safra 2020/2021, a região detentora da maior produção no país é a Nordeste com 424,6 mil toneladas; o estado com maior produção continua sendo o Ceará com 116,3 mil toneladas. Dados relativos a produção de feijão-fava não é tão significativo no Brasil, conforme aborda o Ibge (2020).

As variedades locais sofrem um processo de erosão genética, devido a sua substituição por cultivares selecionadas, cujas quais objetivam aumentar o rendimento econômico (Costa et al., 2013). Para Rocha et al. (2009) o resgate de sementes crioulas é visto como uma excelente alternativa para preservação dessas variedades. Ainda de acordo com os mesmos autores o uso destas variedades pelos agricultores de pequeno porte é uma alternativa sustentável adotada, haja vista que o melhoramento dessas variedades locais pode ser realizado nas próprias propriedades pelos agricultores locais que possuem conhecimento do material utilizado. Além disso as sementes promovem a sobrevivência e produção do próprio alimento de pequenos agricultores (Garcindo, 2009). De acordo com Silva (2017) grande parte da produção de milho crioulo se encontra 
centralizada em localidades, onde, o investimento tecnológico é baixo e em áreas de difícil manejo, em que as sementes crioulas proporcionam aos agricultores familiares excelente alternativa à esta circunstância, quando comparado às cultivares de alta tecnologia que não suportaria dadas condições.

As variedades crioulas tendem a tolerar melhor as variações ambientais, sendo mais resistentes ao ataque de pragas e, por serem adaptadas às condições edafoclimáticas locais (Crisostomo et al., 2018). A diversidade intraespecífica dessas sementes constitui-se em um fator que promove a resiliência aos sistemas produtivos (Londres, 2014). A semente tem papel fundamental na produção agrícola e é um dos insumos mais importantes, seu desempenho é visto como fator essencial para contribuição com o rendimento da cultura significativamente (Silva et al., 2010). Segundo Costa et al. (2013) as sementes de alta qualidade são as que apresentam ótimas características genéticas, físicas, fisiológicas e sanitárias. O uso de sementes crioulas é uma boa alternativa para manutenção do banco de germoplasma de determinadas regiões, se armazenadas de maneira correta (Silva et al., 2012).

A qualidade fisiológica de sementes possui sua base no genótipo, e isso é muito importante no acompanhamento das etapas visando a seleção por meio dos testes de vigor para fins de melhoramento genético (Marcos Filho, 1999). Assim como o genótipo, o ambiente possui papel importante na qualidade de sementes (Gondim et al., 2006). O uso de sementes que apresentem elevado padrão de qualidade física e fisiológica é extremamente importante, por esse motivo, é recomendável aliar métodos eficientes para padronização dos lotes de sementes e testes fisiológicos para analisar a viabilidade dos lotes de sementes (Silva et al., 2008).

Nesse sentido, o objetivo desse trabalho foi avaliar a qualidade física e fisiológica de sementes crioulas de milho e feijão de pequenos agricultores da região de Ituiutaba (MG).

\section{Metodologia}

O trabalho foi conduzido em Ituiutaba (MG) no Laboratório de Análise de Sementes (LASE) da Universidade do Estado de Minas Gerais (UEMG), Unidade de Ituiutaba. Os lotes de sementes foram coletados em Ituiutaba (MG) em pequenas propriedades na zona rural e produtores urbanos locais, safra 2020/2021.

O delineamento experimental utilizado foi o inteiramente casualizado (DIC), sendo os tratamentos compostos por 6 variedades de sementes (1: milho crioulo rural; 2: milho crioulo urbano; 3: milho comercial (Pioneer 3707VYH R3); 4: feijãocaupi; 5: feijão carioca comercial (BRS cultivar estilo); 6: feijão-fava) e 4 repetições de 50 sementes por tratamento, as variedades comerciais foram utilizadas para efeitos de comparação com as crioulas, atuando, portanto, como testemunhas.

Os testes para avaliação da qualidade física foram: peso de mil sementes (PMS) e retenção em peneiras. Para a determinação do PMS utilizaram-se 8 repetições com 100 sementes (4800 sementes no total), onde foram pesadas em balança com precisão de 0,001g. O PMS foi calculado de acordo com a fórmula proposta por Brasil (2009) através da Eq. 1:

Peso de mil sementes $(\mathbf{P M S})=$ peso da amostra $\times 1.000 / n^{\circ}$ total de sementes (1)

$\mathrm{O}$ resultado da determinação foi calculado multiplicando-se por 10 o peso médio obtido das repetições com 100 sementes, o coeficiente de variação não ultrapassou os $4 \%$ para as sementes leguminosas ou $6 \%$ para as sementes palhentas.

Em razão da ausência de peneiras propícias para a realização do teste de uniformidade (retenção em peneiras) para as variedades de feijão na UEMG, Unidade de Ituiutaba, o teste foi empregado somente para as 3 variedades de milho seguindo as RAS (2 repetições de 100g) (Brasil, 2009).

Realizou-se o teste de retenção em peneiras com a pesagem de duas repetições de $100 \mathrm{~g}$ de sementes puras em balança semi-analítica (0,001g), em 4 peneiras: P.23 (13 mm), P.19 (7,5 mm), P.12 (5,0 mm), P.11 (2,5 mm) e fundo, sendo as peneiras dispostas da seguinte forma: colocando o fundo na posição inferior e sobre este a peneira indicada pelo requerente e no topo a peneira imediatamente superior a esta, conforme o que é utilizado na classificação de sementes da espécie em 
análise, nesse caso o milho.

O procedimento prosseguiu inserindo as sementes de uma das repetições sobre a peneira superior agitando por um minuto o conjunto, as sementes retidas pela peneira indicada que passaram pela peneira superior foram separadas e pesadas tendo o seu porcentual calculado.

Para avaliação da qualidade fisiológica das sementes com emergência em papel Germitest®, foram realizados os testes: percentual de germinação (\%G), índice de velocidade de germinação (IVG), primeira contagem de germinação (PCG), comprimento de plântulas (CP) provenientes do teste de germinação e biomassa de plântula (fresca - BF, e seca - BS).

O teste de germinação foi conduzido de acordo com os critérios estabelecidos pelas Regras de Análise de Sementes (RAS). Foram semeadas 50 sementes sobre duas folhas de papel Germitest ${ }^{\circledR}$, cobrindo-as com a terceira folha e, posteriormente umedecidas com volume de 2,5 vezes a massa das 3 folhas secas com solução de $1,5 \%$ de Nistatina $(15 \mathrm{~mL}$ de Nistatina ${ }^{\circledR}+985 \mathrm{~mL}$ de água destilada) (Brasil, 2009). Na sequência os rolos foram confeccionados, acondicionados em sacos plásticos e levados à estufa de germinação com temperatura de $\pm 25^{\circ} \mathrm{C}$ com fotoperíodo de 24 horas. Diariamente foi monitorada a germinação, sendo as contagens realizadas do $4^{\circ}$ ao $7^{\circ}$ dia para o milho, do $5^{\circ}$ ao $8^{\circ}$ dia para feijão-caupi e do $5^{\circ}$ ao $9^{\circ}$ dia para o feijão carioca e feijão-fava (Brasil, 2009). Para considerar uma semente como germinada, levou-se em consideração a emissão da raíz primária.

Primeira contagem de germinação (PCG): foi realizada no $4^{\circ}$ dia após a semeadura para sementes milho e do $5^{\circ}$ dia para sementes de feijão de acordo com o que estabelece as RAS (Brasil, 2009). E após a contagem das plântulas normais, calculou-se a porcentagem de plântulas normais (germinação) para cada repetição de acordo com a fórmula proposta por Nakagawa (1999) e das RAS (Brasil, 2009) elucidada na Eq. 2:

$\%$ Germinação $=\mathrm{P}_{\mathrm{n}} / \mathrm{N}$ x 100

Onde:

$\mathrm{P}_{\mathrm{n}}=$ Plântulas normais

$\mathrm{N}=$ Número total de sementes colocadas para germinar

A média da porcentagem de plântulas normais foi calculada de acordo com cada variedade de milho e feijão.

O índice de velocidade de germinação (IVG) foi calculado seguindo o teste de germinação em papel Germitest®, enquanto o índice de velocidade de emergência (IVE) foi calculado de acordo com o teste de germinação em substrato (areia).

Índice de Velocidade de Germinação: foi realizado concomitantemente ao teste de emergência, calculado através da fórmula proposta por Maguire (1962), computando as plântulas emergidas diariamente até que houvesse a estabilização da emergência das plântulas, conforme evidencia a Eq. 3:

$\mathbf{I V G}=\mathrm{G}_{1} / \mathrm{N}_{1}+\mathrm{G}_{2} / \mathrm{N}_{2}+\ldots \mathrm{G}_{\mathrm{N}} / \mathrm{N}_{\mathrm{N}}$

Onde:

$\mathrm{G}_{1}, \mathrm{G}_{2} \ldots \mathrm{G}_{\mathrm{N}}=$ número de plântulas normais no primeiro, segundo, terceiro até o último dia de contagem, respectivamente; $\mathrm{N}_{1}, \mathrm{~N}_{2} \ldots \mathrm{N}_{\mathrm{N}}=$ número de dias da primeira, segunda, terceira e última contagem, respectivamente.

Comprimento de plântulas (CP): foi medido após o $7^{\circ}$ dia para gramíneas (milho), $8^{\circ}$ (feijão-caupi) e $9^{\circ}$ dia (feijão carioca e feijão-fava) para leguminosas. As plântulas normais foram medidas com auxílio de uma régua, medindo o comprimento total da plântula (para gramíneas) e tomando como medida a ponta da raíz até a inserção dos cotilédones (para leguminosas) (Sa et al., 2011). Posteriormente foi calculado o comprimento médio de plântulas (Eq. 4).

$\mathbf{C P}_{\mathbf{m}}=\mathrm{CP}_{1}+\mathrm{CP}_{2}+\ldots+\mathrm{CP}_{\mathrm{n}} / \mathrm{P}_{\mathrm{n}}$

Onde:

$\mathrm{CP}_{\mathrm{m}}=$ comprimento médio das plântulas

$\mathrm{CP}_{1}, \mathrm{CP}_{2}, \mathrm{CP}_{\mathrm{n}}=$ comprimento de plântula normal 
$\mathrm{P}_{\mathrm{n}}=$ número de plântulas normais mensuradas

Biomassa Fresca (BF) e Seca (BS): após a última contagem de emergência em papel Germitest®, as plântulas foram separadas e pesadas para determinação da biomassa fresca de acordo com as repetições em balança analítica com precisão de 0,0001g, o peso de cada repetição foi dividido pelo número de plântulas. Em seguida, com auxílio de uma lâmina os cotilédones foram retirados e a plântula (parte aérea e raíz) foram colocadas em um recipiente metálico previamente pesado e separado por tratamento e repetição (Sa et al., 2011). O material foi colocado para secar em estufa termoelétrica com temperatura regulada de $65^{\circ} \mathrm{C}$ por um período de 72 horas.

Posterior a esse período, as amostras foram retiradas da estufa e colocadas para esfriar; em seguida as amostras foram pesadas em balança analítica com precisão de 0,0001g. A determinação da biomassa seca total das plântulas normais foi realizada através da Eq. 5 abaixo. E o resultado foi expresso em mg plântula ${ }^{-1}$.

\section{BS plântulas = Ps/N x 1000}

Onde:

BS = Biomassa seca de plântulas normais;

$\mathrm{N}$ = número de plântulas normais.

Para emergência em substrato, utilizou-se areia média previamente peneirada e acondicionada em bandejas de propileno com quantidade suficiente para um nível de $3 \mathrm{~cm}$ de altura no interior das bandejas. O substrato foi pesado, desconsiderando-se o peso das bandejas e em seguida as sementes foram distribuídas de forma equidistante com espaçamento de 1,0 a 5,0 vezes a largura e diâmetro das sementes (Sa et al., 2011). As bandejas foram identificadas de acordo com o nome da espécie, tratamento e repetição em fita adesiva colada na lateral e região de fácil visualização. As sementes foram cobertas com uma camada de substrato $(1 \mathrm{~cm})$ e umedecidas com água destilada na quantidade de $60 \%$ (para milho e leguminosas) da capacidade de retenção do substrato seguindo as Regras de Análise de Sementes (Brasil, 2009).

As bandejas ficaram em ambiente com iluminação e temperatura ambiente, sendo verificado a cada 2 dias a necessidade de água para umedecimento do substrato (Sa et al., 2011). A germinação foi monitorada diariamente com contagens realizadas do $4^{\circ}$ ao $7^{\circ}$ dia para milho, do $5^{\circ}$ ao $8^{\circ}$ dia para feijão-caupi e do $5^{\circ}$ ao $9^{\circ}$ dia para feijão carioca e feijãofava (Brasil, 2009). Considerou-se como plântula emergida de milho quando observada a emissão do epicótilo, e para o feijão, quando observou-se a emissão das folhas primárias. Os parâmetros analisados foram: Índice de velocidade de emergência (IVE) e percentual de germinação (\%G).

Índice de Velocidade de Emergência: foi calculado sem que houvesse a retirada das plântulas normais do substrato; portanto, nas avaliações diárias o número de plântulas obtidas em cada dia correspondeu ao valor cumulativo (Sa et al., 2011). Sendo assim, o número de plântulas normais efetivo do dia considerado de contagem foi subtraído ao valor lido do dia anterior, conforme expõe a Eq. 6, proposta por Sa et al. (2011).

$$
\mathbf{I V E}=\mathrm{G}_{1} / \mathrm{N}_{1}+\left(\mathrm{G}_{2}-\mathrm{G}_{1}\right) / \mathrm{N}_{2}+\left(\mathrm{G}_{3}-\mathrm{G}_{2}\right) / \mathrm{N}_{2}+\ldots+\left(\mathrm{G}_{\mathrm{f}}-\mathrm{G}_{\mathrm{n}}\right) / \mathrm{N}_{\mathrm{f}}
$$

Onde:

IVE $=$ Índice de velocidade de emergência

$\mathrm{G}_{1}, \mathrm{G}_{2}, \mathrm{G}_{3}, \mathrm{G}_{\mathrm{n}}$ e $\mathrm{G}_{\mathrm{f}}=$ número de plântulas normais emergidas na primeira contagem, na segunda, terceira, demais dias e na última contagem, respectivamente;

$\mathrm{N}_{1}, \mathrm{~N}_{2}, \mathrm{~N}_{3}, \mathrm{~N}_{\mathrm{n}}$ e $\mathrm{N}_{\mathrm{f}}=$ número de dias de semeadura da primeira, segunda, terceira, demais e última contagem, respectivamente.

Os dados foram submetidos à análise de variância (ANOVA), e as médias foram comparadas pelo teste Tukey a 5\% de probabilidade de erro utilizando o software estatístico: Sisvar versão 5.8 (Build 92) (Ferreira, 2011). 


\section{Resultados e Discussão}

Observou-se que os resultados apresentaram diferença estatística significativa para o parâmetro PMS entre as variedades crioulas de milho e feijão. Os dados correspondentes ao PMS são ilustrados na Figura 1.

Figura 1 - Peso de mil sementes (g) das variedades de milho e feijão. Ituiutaba, MG, 2021.

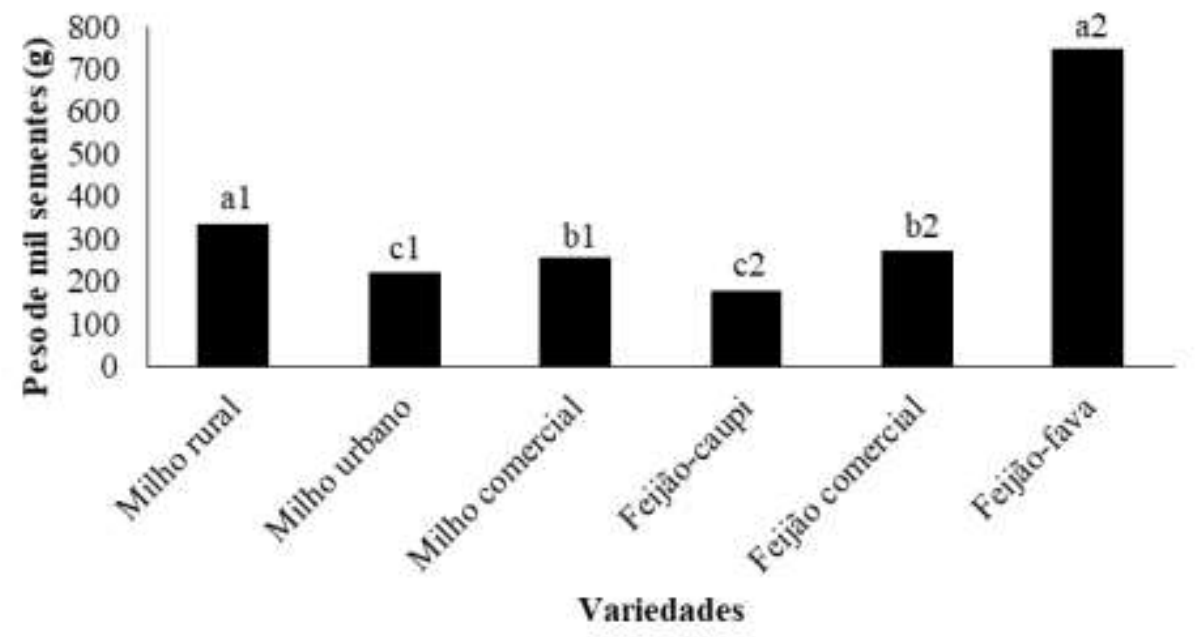

Obs.: médias seguidas pela mesma letra não diferem entre sí pelo teste de Tukey a 5\% de probabilidade. Fonte: Autores.

O Feijão-fava destacou-se entre os demais, tendo em vista suas características inerentes à espécie. De acordo com Vasquez et al. (2012), alterações no tamanho das sementes interferem somente no desenvolvimento inicial de plântulas. Para Pádua et al. (2010), as sementes com tamanho maior apresentam correlações positivas com desenvolvimento inicial de plântulas, favorecendo o rápido crescimento das raízes e da parte aérea e, promovendo um aproveitamento melhor das reservas hídricas e nutricionais de solo, bem como maior potencial de produtividade.

Considerando-se as variedades de milho, o milho rural se destacou dentre os demais; resultado similar foi encontrado por Limão (2019) para a variedade crioula Asa branca e por Silva (2020) para 9 lotes em seu trabalho com 24 lotes de sementes crioulas e 1 comercial. O menor valor de PMS ficou com o milho urbano. O milho comercial não obteve tanto destaque quando comparado às variedades de milho crioulo e o resultado ainda foi inferior ao calculado por Silva (2020) para a cultivar comercial (A25). Por outro lado, quando comparado à variedade Ibra, o resultado foi praticamente idêntico ao calculado por Limão (2019) em seu trabalho. Em contrapartida, comparando-se as variedades de feijão, ganha destaque o feijão-fava, cujas sementes são visualmente maiores que as demais variedades. O trabalho conduzido por Silva (2017) demonstrou resultado muito próximo para a variedade crioula manteiga de feijão-fava. A variedade crioula de feijão-caupi apresentou-se com valor inferior as demais. Já a cultivar BRS estilo destacou-se com PMS mediano, mas ainda assim foi superior às variedades testadas por Berto et al. (2018).

Outra variável muito importante dentro do teste de qualidade física das sementes é o teste de retenção em peneiras (RP) que está diretamente relacionado à massa dos grãos e influencia na uniformidade dos lotes de sementes em razão do tamanho e densidade, minimizando a heterogeneidade do lote e padronizando-o. Os resultados não apresentaram diferença estatística significativa entre as variedades de milho, observou-se que entre as variedades de milho a RP (\%) foi maior para a P.19, seguida em menor RP (\%) pela P.12. As peneiras P.23, P.11 e fundo não apresentaram sementes retidas, portanto, o valor analisado nesse caso foi de $0 \%$.

Para avaliação da qualidade fisiológica os resultados mostraram que os menores valores de IVE e \%G foi observado para a variedade de feijão-fava crioulo (4,18 e 66,5\%, respectivamente). Entre as variedades de milho, o IVE variou de 6,45 a 
12,22 e o \%G variou de 76 a 92\%, enquanto que para as variedades de feijão, a variação foi de 4,18 a 8,08 para o IVE e de 66,5 a 93\% para o \%G. Os resultados para as variáveis índice de velocidade de emergência (IVE) e percentual de germinação $(\% \mathrm{G})$ estão dispostos nas Tabelas 1 e 2. Observou-se que apesar de não apresentar diferenças estatísticas para o \%G entre as variedades de milho urbano e feijão comercial, o vigor da variedade de milho urbano foi superior a de feijão comercial, haja vista a diferença estatística significativa para o IVE entre os tratamentos. Isso significa que haverá reflexos na performance a nível de campo.

Tabela 1 - Médias das variáveis: Índice de velocidade de emergência e percentual de germinação de sementes crioulas de milho para o teste em substrato (areia).

\begin{tabular}{|c|c|c|}
\hline Variedades & IVE & $\% \mathrm{G}$ \\
\hline Milho rural & $8,07 \mathrm{~b}$ & $83,5 \mathrm{a}$ \\
\hline Milho urbano & $12,22 \mathrm{a}$ & $92,0 \mathrm{a}$ \\
\hline Milho comercial & $6,45 \mathrm{~b}$ & $76,0 \mathrm{a}$ \\
\hline CV (\%) & 13,76 & 10,87 \\
\hline
\end{tabular}

Obs.: Médias seguidas pela mesma letra na coluna, não difere entre si pelo teste de Tukey a 5\% de probabilidade de erro. IVE: Índice de velocidade de emergência; \%G: Percentual de germinação; CV: Coeficiente de variância.

Fonte: Autores.

Quanto maior o IVE, mais vigoroso é o lote de sementes testados, indicando maior capacidade de originar plântulas competitivas na fase inicial de desenvolvimento da cultura (Berto et al., 2018). Existe correlação positiva entre o IVE e \%G, quanto maior for o \%G maior será o IVE (Silva, 2020). Na avaliação do IVE, o milho urbano apresentou maior velocidade de emergência $(12,22)$ entre as variedades de milho demonstrando que são mais vigorosas e o resultado foi muito próximo para 4 lotes analisados por Silva (2020) em seu estudo com sementes crioulas de milho; ainda assim, o resultado de IVE para o milho urbano foi superior ao da variedade comercial (testemunha). A variedade comercial de milho apresentou IVE mediano comparado às demais sementes, esperava-se que a qualidade fisiológica fosse superior já que os cuidados tomados durante o processo de produção de sementes são elevados, o milho rural não diferenciou estatisticamente do milho comercial.

De acordo com a instrução normativa $n^{\circ} 45$ da Associação Brasileira de Sementes e Mudas (ABRASEM), o percentual mínimo de germinação para sementes de milho é de $75 \%$ para sementes básicas e de $85 \%$ para sementes certificadas de primeira geração (C1), segunda geração (C2), sementes fiscalizadas de primeira geração (S1) e segunda geração (S2); 70\% para sementes básicas e $80 \%$ para sementes C1, C2, S1 e S2 de feijão comum e feijão-caupi (Abrasem, 2013). Nesse sentido, ressalta-se que as sementes vendidas aos produtores são certificadas (C1 e C2) e fiscalizadas (S1 e S2). O milho comercial atingiu o percentual mínimo de germinação recomendado para sementes básicas (76\%). Ainda assim, o resultado foi próximo à cultivar do lote comercial A25 (79\%) testada por Silva (2020) no seu trabalho com sementes crioulas de milho. Apesar das variedades de milho apresentarem \%G médio inferior a 85\%, o milho urbano apresentou \%G idêntico ao encontrado por Miranda et al. (2003) ao caracterizarem populações de milho crioulo da região de Minas Gerais com germinação média de 92\%; os lotes crioulos de milho A3 e A23 analisados por Silva (2020) corroboram os resultados encontrados no presente estudo. Entre as sementes crioulas de milho, todas as variedades atingiram o percentual mínimo de germinação que é recomendado para a comercialização de sementes básicas. 
Tabela 2 - Médias das variáveis: Índice de velocidade de emergência e percentual de germinação de sementes crioulas de feijão para o teste em substrato (areia).

\begin{tabular}{lcc}
\hline \multicolumn{1}{c}{ Variedades } & IVE & \%G \\
\hline Feijão-caupi & $8,08 \mathrm{a}$ & $84,5 \mathrm{a}$ \\
Feijão comercial & $7,51 \mathrm{a}$ & $93,0 \mathrm{a}$ \\
Feijão-fava & $4,18 \mathrm{~b}$ & $66,5 \mathrm{a}$ \\
\hline \multicolumn{1}{c|}{ CV (\%) } & 4,96 & 5,48 \\
\hline
\end{tabular}

Obs.: Médias seguidas pela mesma letra na coluna, não difere entre si pelo teste de Tukey a 5\% de probabilidade de erro. IVE: Índice de velocidade de emergência; \%G: Percentual de germinação; CV: Coeficiente de variância.

Fonte: Autores.

Entre as variedades de feijão, o feijão-caupi se destacou com maior velocidade de emergência $(8,08)$. Apesar das variedades de feijão não terem apresentado IVE elevado, variedades de feijão-caupi e comercial (testemunha) não diferenciaram-se entre si pelo teste de Tukey a 5\% de probabilidade de erro, ainda assim, os resultados do IVE para as variedades de feijão foram superiores ao encontrado por Berto et al. (2018). O feijão comercial (BRS cv. estilo) apresentou resultado próximo ao calculado por Bueno (2020) em seu trabalho com cultivares de feijão BRS Esteio (7,93) na região Centro-oeste do país. O feijão comercial, apresentou desempenho significativo quando observado os dados para \%G (93\%). Por outro lado, a variedade de feijão-fava foi a única dentre as demais variedades de feijão com menor \%G. Em seu estudo realizado com sementes crioulas de feijão-fava nas diferentes regiões do Centro-oeste e Sul do país, Coelho et al. (2015) observaram que o percentual de germinação variou de $96 \%$ a $100 \%$, diferenciando das sementes crioulas de feijão-fava testadas no presente estudo que conferiram menor $\% \mathrm{G}(66,5 \%)$. Ainda assim, o resultado foi muito próximo ao encontrado por Silva (2017) para a variedade de feijão-fava olho de cabra com germinação de $72 \%$.

Os testes de germinação em papel Germitest ${ }^{\circledR}$ são fundamentais para quantificar o vigor das sementes, no entanto, os padrões germinativos das sementes (Tabelas 3 e 4) não foram tão significativos, apresentando elevado percentual de plântulas anormais (PA), demonstrando que o vigor das sementes é baixo, afetando a performance das plantas em relação a produção a nível de campo. A primeira contagem de germinação (PCG) é uma variável diretamente relacionada com o vigor do lote de sementes.

Tabela 3 - Médias das variáveis: Primeira Contagem de germinação (\%); Plântulas Normais (\%); Plântulas Anormais (\%); Sementes Não Germinadas (\%); Índice de velocidade de germinação; Percentual de germinação de sementes crioulas de milho de Ituiutaba-MG.

\begin{tabular}{lcccccc}
\hline \multicolumn{1}{c}{ Variedades } & \multicolumn{5}{c}{ Variáveis } \\
\cline { 2 - 7 } & PCG & PN & PA & SNG & IVG & \%G \\
\hline Milho rural & $65,0 \mathrm{a}$ & $2,5 \mathrm{a}$ & $76,0 \mathrm{ab}$ & $17,5 \mathrm{ab}$ & $1,90 \mathrm{a}$ & $78,5 \mathrm{ab}$ \\
Milho urbano & $65,5 \mathrm{a}$ & $3,5 \mathrm{a}$ & $85,5 \mathrm{a}$ & $12,0 \mathrm{~b}$ & $2,66 \mathrm{a}$ & $89,0 \mathrm{a}$ \\
Milho comercial & $33,5 \mathrm{~b}$ & $8,0 \mathrm{a}$ & $55,5 \mathrm{~b}$ & $36,5 \mathrm{a}$ & $6,08 \mathrm{a}$ & $63,5 \mathrm{~b}$ \\
\hline \multicolumn{1}{c}{ CV (\%) } & 12,00 & 57,59 & 16,09 & 47,65 & 57,54 & 14,98 \\
\hline
\end{tabular}

Obs.: Médias seguidas pela mesma letra na coluna não difere entre si pelo teste de Tukey a 5\% de probabilidade de erro. PCG: Primeira Contagem de Germinação; PN: Plântulas Normais; PA: Plântulas Anormais; SNG: Sementes não Germinadas; IVG: Índice de Velocidade de Germinação; \%G: Percentual de Germinação.

Fonte: Autores.

Para Feitosa et al. (2018) a PCG é um dos indicadores importantes para apontar o estabelecimento de populações de plantas no campo. Entre as variedades de milho crioulo, a variedade comercial foi a que apresentou-se como menos vigorosa entre todas as variedades, indicando baixa capacidade de formação da lavoura a nível de campo. As variedades rural e urbana de milho crioulo não diferenciaram entre sí pelo teste de Tukey a 5\% de probabilidade de erro, mas destacaram-se entre as variedades de milho crioulo com PCG mediano, no entanto, Pereira (2020) ao realizar a caracterização de sementes crioulas do 
Alto Sertão Sergipano, encontrou resultado inferior para PCG da variedade de milho crioulo Cateto $(55,0 \%)$. Esse teste (PCG) possibilita indicar as sementes com elevado vigor já na primeira contagem (Silveira, Villela \& Tillmann, 2002).

Segundo Guedes et al. (2015) além dos testes de germinação (\%G) e PCG, são utilizados para avaliação de vigor das sementes em campo e laboratório, os testes baseados no desempenho das plântulas, como: quantidades de plântulas anormais (PA), sementes não germinadas (SNG), IVG (índice de velocidade de germinação), comprimento de plântulas (CP) e biomassa seca (BS). Entre as variedades de milho crioulo, o milho rural foi que obteve maior SNG, tendo o milho comercial se destacado negativamente para essa variável com maior SNG entre as variedades de milho e feijão, além de apresentar \%G inferior às demais variedades de milho. $\mathrm{O} \% \mathrm{G}$ foi superior para a variedade de milho urbano, o resultado foi praticamente o mesmo encontrado por Pereira (2020) em seu estudo com a variedade de milho crioulo vermelho no Alto Sertão Sergipano. Os resultados de \% G das variedades de milho foram inferiores aos relatados por Limão (2019) em seu trabalho com sementes crioulas de milho. A variedade comercial de milho (Pioneer 3707VYH R3) apresentou menor \%G (63,5\%) entre todas as variedades; ainda assim, o resultado ficou próximo ao avaliado por Silva (2020) no lote A11 (68\%) em seu trabalho com testes tradicionais e com auxílio de análise de imagens para as sementes crioulas de milho. Em lado oposto, Queiroz et al. (2019) ao avaliarem a qualidade fisiológica de sementes crioulas de milho no Mato Grosso obteve \%G médio de $97 \%$.

Tabela 4 - Médias das variáveis: Primeira Contagem de germinação (\%); Plântulas Normais (\%); Plântulas Anormais (\%); Sementes Não Germinadas (\%); Índice de velocidade de germinação; Percentual de germinação de sementes crioulas de feijão de Ituiutaba-MG.

\begin{tabular}{lcccccc}
\hline \multicolumn{1}{c}{ Variedades } & \multicolumn{4}{c}{ Variáveis } \\
\cline { 2 - 7 } & PCG & PN & PA & SNG & IVG & \%G \\
\hline Feijão-caupi & $82,5 \mathrm{a}$ & $4,0 \mathrm{a}$ & $88,0 \mathrm{a}$ & $8,0 \mathrm{a}$ & $2,54 \mathrm{a}$ & $92,0 \mathrm{a}$ \\
Feijão comercial & $82,5 \mathrm{a}$ & $5,5 \mathrm{a}$ & $88,5 \mathrm{a}$ & $6,0 \mathrm{a}$ & $4,10 \mathrm{a}$ & $93,5 \mathrm{a}$ \\
Feijão-fava & $52,5 \mathrm{~b}$ & $0,0 \mathrm{a}$ & $84,5 \mathrm{a}$ & $15,5 \mathrm{a}$ & $0,75 \mathrm{a}$ & $84,5 \mathrm{a}$ \\
\hline \multicolumn{1}{c}{ CV (\%) } & 11,06 & 87,63 & 7,58 & 51,08 & 98,08 & 5,15 \\
\hline
\end{tabular}

Obs.: Médias seguidas pela mesma letra na coluna não difere entre si pelo teste de Tukey a 5\% de probabilidade de erro. PCG: Primeira Contagem de Germinação; PN: Plântulas Normais; PA: Plântulas Anormais; SNG: Sementes não Germinadas; IVG: Índice de Velocidade de Germinação; \%G: Percentual de Germinação.

Fonte: Autores.

A variedade crioula de feijão-caupi e comercial de feijão (BRS cv. estilo) demonstraram-se como mais vigorosas entre as variedades analisadas. Resultado idêntico é relatado por Santos et al. (2015) em seu trabalho com sementes de 4 cultivares de feijão comum na microrregião de Ceres-GO, no lote com cultivar BRS Esplendor (82,5\%). Ainda considerando-se a PCG, Amaro et al. (2015) estudando diferentes lotes de sementes de feijão comum, cultivar Madrepérola observaram que o lote 1 (82\%) foi muito próximo ao encontrado no presente trabalho. Entretanto, o elevado número de PA e SNG evidencia que todas as variedades analisadas têm demonstrado baixo vigor, podendo resultar em desuniformidade no campo, causando falhas e afetando na produção. Em relação ao \%G, as variedades de feijão-caupi e comercial se destacaram dentre as demais, contudo, o percentual de plântulas normais foi muito baixo em todas as variedades, indicando que possíveis danos fisiológicos podem ter acometido as sementes para resultar em baixo potencial fisiológico nos testes de laboratório. Por outro lado, o PA foi elevado para as variedades de milho e feijão, assim como o SNG.

Comparando-se as variáveis \%G com PN, PA e SNG, verificou-se que a grande maioria das sementes germinadas não possuíam todas as estruturas essenciais bem desenvolvidas, portanto, o percentual de plântulas anormais (PA) foi muito elevado. Mesmo apresentando menor \%G, o milho comercial foi a variedade que mais apresentou PN (8\%), Menezes et al. (2020) observaram diferenças nos resultados de PN de variedades de milho crioulo, variando de 6\% a 90\%. Em contrapartida, o PA analisado neste trabalho foi muito alto, diferentemente do encontrado por Menezes et al. (2020), onde o PA variou de 1 a 
13\%. Para o milho comercial também ficou evidente que o número de SNG foi muito alto, indicando que a quantidade de sementes duras $(36,5 \%)$ elevada tem relação com o comportamento fisiológico possivelmente afetado durante alguma etapa de beneficiamento e/ou armazenamento das sementes. Entre as variedades de milho, o milho urbano apresentou SNG mais baixo.

O IVG é um parâmetro utilizado para determinação do vigor dos lotes de semente e, notou-se entre as variedades que o milho comercial apresentou maior IVG $(6,08)$, no entanto, não houve diferença estatística entre as demais variedades de milho. Os resultados indicam que o milho comercial possui maior potencial fisiológico dentre as variedades estudadas e, tendem a apresentar plântulas com mais rápida emergência de maneira uniforme no campo (Oliveira et al., 2011). Para as variedades crioulas de milho, o milho urbano apresentou IVG de 2,66. Resultado muito próximo foi encontrado por Menezes et al. (2020) para a variedade Catetão $(2,72)$ ao estudarem o potencial fisiológico de sementes de milho armazenadas por pequenos agricultores em Euclides da Cunha/BA. Pereira (2020) observou que os lotes de cinco variedades de milho crioulo apresentaram IVG superior, variando de 6,77 para a variedade Cateto a 20,46 para a variedade de milho doce. No trabalho desenvolvido por Silva (2020) avaliando sementes de milho crioulo, percebeu-se que quanto maior o \%G, maior o IVG. O milho rural apresentou IVG inferior $(1,90)$, esse parâmetro evidenciou que essa variedade possui menor desempenho fisiológico (Sena, Alves \& Medeiros, 2015).

Para as variedades de feijão, não houve diferença estatística significativa para o \%G, porém, as variedades de feijãocaupi e de feijão comercial mostraram-se mais vigorosas que o feijão-fava. Apesar de apresentarem elevado \%G, Batista et al. (2012) em seu trabalho de avaliação da qualidade fisiológica de sementes de feijão-caupi através do teste de condutividade elétrica obtiveram resultados superiores ao calculado no presente trabalho. O feijão comercial apresentou elevado \%G (93,5\%); o resultado foi superior ao encontrado por Silva et al. (2008) na avaliação de 9 cultivares de feijão provenientes do estado de Goiás. Santos et al. (2015) verificaram para sementes de 4 cultivares de feijão comum no estado de Goiás, \%G variando de $62 \%$ a $84 \%$. O feijão-fava não diferenciou entre as variedades de feijão, mas ainda assim, foi o que apresentou menor resultado para a variável \%G, Silva (2017) observou em seu trabalho para a variedade de feijão-fava olho de cabra resultado inferior (72\%), porém, para as demais variedades os resultados foram amplamente superiores ao encontrado nesse trabalho. Advíncula et al. (2015) ao trabalharem com sementes crioulas de feijão-fava (Marronzinha, Leite, Anduzinha e Orelha de Vó) obtiveram $85 \%$ de \%G para a variedade Orelha de vó, resultado esse muito próximo ao encontrado para o lote 6.

Entre as variedades de feijão, a variação entre o SNG foi significativa sendo $6 \%$ (feijão comercial) e 15,5\% (feijãofava). O resultado de SNG da variedade de feijão comercial foi idêntico ao analisado por Santos et al. (2015) para a cultivar BRS Pitanga; esse resultado de SNG em consonância com PA influenciaram diretamente no \%G. A quantidade de PN foi inferior ao observado por Silva et al. (2008), onde o menor valor de PN foi encontrado para o feijão jalo precoce (3,37\%), o feijão comercial apresentou PN de 5,5\%, resultado esse muito inferior ao observado por Silva et al. (2008) para as cultivares BRS Radiante $(56,25 \%)$ e BRS Talismã $(45,07 \%)$.

As variedades de feijão obtiveram resultados inferiores às de milho para a variável IVG. O feijão-caupi foi que maior IVG $(4,10)$ apresentou entre as variedades de feijão, demonstrando, portanto, que a capacidade de apresentar plântulas com maior rapidez na germinação e uniformidade no campo é superior. Esse resultado foi inferior para as variedades: Sedinha $(5,13)$, Corujinha $(5,38)$ e Azul $(5,46)$ observado por Silva et al. (2019) ao analisarem a qualidade fisiológica e física de sementes crioulas de feijão em Campina Grande/PB. O menor valor de IVG foi observado para o feijão-fava (0,75) apresentando desenvolvimento mais lento que as demais sementes, tal fato é destacado por Derre et al. (2017) que afirmam que sementes maiores têm mais dificuldade de desenvolverem tanto raízes como parte aérea, quando comparado às sementes menores.

Ao estudarem o vigor de sementes crioulas de feijão, Chagas et al. (2018) fizeram a comparação entre as cultivares: cabeça-de-gato e rosinha, ambas mostraram comportamentos diferentes, sendo que as sementes maiores (cabeça-de-gato) 
apresentaram baixo IVG $(1,75)$, enquanto a cultivar rosinha com sementes menores, apresentou maior IVG (17,25). Silva (2017) observou menor IVG para a variedade de feijão-fava crioula Olho de Cabra $(8,0)$, porém, esse valor foi muito superior ao encontrado no presente estudo. A variedade de feijão-caupi apresentou IVG: 2,54, e não diferenciou estatisticamente das demais variedades de feijão. Pinho e Cunha (2019) ao avaliarem a qualidade fisiológica de sementes de feijão-caupi observaram resultados superiores em todos os 14 lotes de feijão-caupi para a variável IVG, que variou de 7,28 (T11) a 8,84 (T7).

Com relação ao Comprimento médio de plântulas (CP) (Tabelas 5 e 6), observou-se que não houve diferença estatística significativa para as variedades de milho, a variação em $\mathrm{cm}$ planta $^{-1}$ foi baixa $(7,04$ a 8,93). Não obstante, para as variedades de feijão notou-se diferenças estatísticas significativas entre as variedades de feijão-caupi e feijão-fava (9,01 e 4,60, respectivamente), mas não houve diferença entre as variedades de feijão-caupi e feijão comercial (9,01 e 9,87, respectivamente).

Tabela 5 - Médias das variáveis: Comprimento médio de Plântulas ( $\left.\mathrm{cm}_{\text {planta }}{ }^{-1}\right)$; Biomassa Fresca (g plântula $\left.{ }^{-1}\right)$; Biomassa Seca (mg plântula $\left.{ }^{-1}\right)$; Condutividade elétrica $\left(\mu \mathrm{S} \mathrm{cm}^{-1} \mathrm{~g}^{-1}\right)$ de sementes crioulas de milho no Município de Ituiutaba-MG.

\begin{tabular}{lcccc}
\hline \multicolumn{1}{c}{ Variedades } & CP & BF & BS & CE \\
\hline Milho rural & $7,04 \mathrm{~b}$ & $0,370 \mathrm{a}$ & $36,72 \mathrm{a}$ & $25,94 \mathrm{~b}$ \\
Milho urbano & $8,94 \mathrm{a}$ & $0,398 \mathrm{a}$ & $38,63 \mathrm{a}$ & $34,33 \mathrm{a}$ \\
Milho comercial & $8,93 \mathrm{a}$ & $0,301 \mathrm{~b}$ & $33,15 \mathrm{a}$ & $36,53 \mathrm{a}$ \\
\hline \multicolumn{1}{c}{ CV $(\%)$} & 5,94 & 3,82 & 45,61 & 6,39 \\
\hline
\end{tabular}

Obs.: Médias seguidas pela mesma letra na coluna não difere entre si pelo teste de Tukey a 5\% de probabilidade de erro. CP: Comprimento de Plântulas; BF: Biomassa Fresca; BS: Biomassa Seca; CE: Condutividade Elétrica.

Fonte: Autores.

Apresentou-se entre as variedades de milho pouca variação entre os dados para CP, não apresentando diferença estatística significativa. Silva (2020) ao analisar a qualidade fisiológica de sementes crioulas de milho em Mossoró/RN, encontrou resultados muito próximos às variedades crioulas de milho (rural e urbano), onde os resultados de 4 variedades se aproximaram ao analisado na variedade de milho rural, e a variedade $3\left(8,49 \mathrm{~cm}_{\text {planta }}{ }^{-1}\right)$ que mais se aproximou do milho urbano $\left(8,94 \mathrm{~cm}\right.$ planta $\left.^{-1}\right)$. O milho urbano apresentou resultado praticamente semelhante ao milho comercial $(8,93 \mathrm{~cm}$ planta$\left.{ }^{1}\right)$. De acordo com Limão (2019) o comprimento médio de plântulas de milho crioulo $\left(8,65 \mathrm{~cm}^{2}\right.$ planta $\left.^{-1}\right)$ se aproximou dos resultados encontrados nas variedades de milho urbano e comercial. Pereira (2020) salienta que é através da BF e BS que consegue-se determinar a qualidade dos lotes de sementes. Para a variável BF não foi observada diferença estatística significativa entre as variedades de sementes de milho. A variação na BF foi de $0,301 \mathrm{~g}$ plântula ${ }^{-1}$ a $0,398 \mathrm{~g}_{\text {plântula }}{ }^{-1}$, esses resultados foram inferiores ao analisado por Pereira (2020) nas variedades crioulas de milho no Alto Sertão Sergipano.

As avaliações de BS das plântulas têm suma importância na análise de desenvolvimento, assegurando o desenvolvimento destas no campo (Ramos et al., 2004). Entre as variedades de milho não houve discrepância para os resultados de BF e BS, para a BS não houve diferença estatística entre as variedades analisadas. Os resultados de BS para as variedades de milho foram inferiores para o milho comercial em relação à cultivar de milho comercial lote A25 analisada por Silva (2020) em seu trabalho com 24 lotes de sementes crioulas e 1 lote comercial, assim como, os resultados de BS das variedades de milho rural e urbano. O teste de condutividade elétrica (CE) avalia a permeabilidade seletiva das membranas, de forma que quando observa-se o menor resultado obtido, deduz-se que o nível de organização das membranas é maior (Rosa, 2020).

O CE é amplamente utilizado em programas de controle de qualidade de sementes (Vieira \& Krzyzanowski, 1999). Limão (2019) ao avaliar a CE de variedades crioulas de milho (Asa Branca, Ibra e Pe. Cícero) e comercial (AG 1051) observou 
resultados inferiores, portanto, as sementes analisadas por ele possuem vigor superior a todos os lotes de milho analisados. Ainda de acordo com Limão (2019) o resultado superior para a variedade de milho comercial é resultante do emprego de tecnologias e aplicação de fungicidas para o tratamento das sementes implicando em maior aderência dos lixiviados na superfície da semente, possibilitando incremento de CE. Observou-se que o milho rural é mais vigoroso que o milho comercial (testemunha) diferindo estatisticamente, apresentando menor valor de $\mathrm{CE}$, em sentido oposto, o milho urbano não diferiu estatisticamente do milho comercial, demonstrando, portanto, que ambos têm menor vigor que o milho rural para CE.

Tabela 6 - Médias das variáveis: Comprimento médio de Plântulas ( $\left.\mathrm{cm}_{\text {planta }}^{-1}\right)$; Biomassa Fresca (g plântula $\left.{ }^{-1}\right)$; Biomassa Seca (mg plântula ${ }^{-1}$ ); Condutividade elétrica $\left(\mu \mathrm{S} \mathrm{m}^{-1} \mathrm{~g}^{-1}\right)$ de sementes crioulas de feijão no Município de Ituiutaba-MG.

\begin{tabular}{lcccc}
\hline \multicolumn{1}{c}{ Variedades } & CP & BF & BS & CE \\
\hline Feijão-caupi & $9,01 \mathrm{a}$ & $0,556 \mathrm{ab}$ & $44,43 \mathrm{ab}$ & $229,56 \mathrm{a}$ \\
Feijão comercial & $9,87 \mathrm{a}$ & $0,724 \mathrm{a}$ & $62,34 \mathrm{a}$ & $0,16 \mathrm{~b}$ \\
Feijão-fava & $4,60 \mathrm{~b}$ & $0,307 \mathrm{~b}$ & $33,84 \mathrm{~b}$ & $0,08 \mathrm{~b}$ \\
\hline \multicolumn{1}{c}{ CV (\%) } & 17,79 & 17,80 & 19,13 & 16,32 \\
\hline
\end{tabular}

Obs.: Médias seguidas pela mesma letra na coluna não difere entre si pelo teste de Tukey a 5\% de probabilidade de erro. CP: Comprimento de Plântulas; BF: Biomassa Fresca; BS: Biomassa Seca; CE: Condutividade Elétrica.

Fonte: Autores.

Em sentido oposto, as variedades de feijão destacaram-se com maior CP (feijão comum BRS Estilo) e menor CP (feijão-fava). Franzin et al. (2004) observaram que o uso do teste de CP não mostrou sensibilidade suficiente para indicar diferenças capazes de diferenciar os lotes separando-os pelo vigor. Firmino (2017) ao estudar a emergência e vigor de cultivares de feijão-caupi em Mossoró/RN encontrou resultado de CP superior às variedades de feijão no presente estudo. Nascimento (2020) trabalhando os aspectos genéticos e qualidade fisiológica de sementes crioulas de feijão-fava observou que os resultados foram, no geral, superiores para CP das variedades de feijão-fava, mas a variedade Rainha obteve comportamento

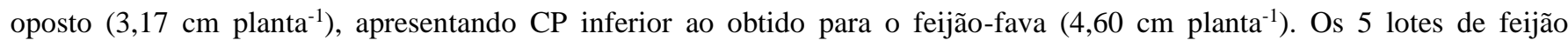
analisados por Amaro et al. (2015) apresentaram CP muito superiores aos estudados nesse trabalho, demonstrando, portanto, qualidade melhor.

A BF nas variedades de feijão apresentou diferenças estatísticas entre as variedades, sendo o feijão-fava com valor inferior à variedade de feijão comercial (testemunha) para essa variável. Esse valor foi inferior ao calculado por Silva (2018) em seu trabalho sobre a qualidade física e fisiológica de sementes crioulas de feijão, assim como as demais variedades de feijão (feijão-caupi e feijão comercial) analisado no presente estudo. A variedade de feijão comercial se destacou entre todas as variedades com maior BF, porém, estatisticamente não houve diferença para a variedade de feijão-caupi. Firmino (2017) observou variação entre as 6 variedades crioulas de feijão-caupi, mesmo assim os resultados foram muito superiores aos observados para a variedade de feijão-caupi. Maia et al. (1986) atribuem o baixo sucesso do feijão-caupi às variedades tradicionais, que possuem baixa qualidade genética.

Segundo Ludwig et al. (2011) a BS das plântulas tem por objetivo determinar a transferência de reservas para o embrião. Para as variedades de feijão observou-se diferenças estatísticas para a variável BS entre as variedades de feijão comercial e feijão-fava, com maior destaque para o feijão comercial. Ao avaliarem a qualidade de sementes crioulas de feijão por meio de testes de vigor, Amaro et al. (2015) encontraram resultados superiores para BF e BS em diferentes lotes de sementes de feijão comum. Para as variedades de feijão os resultados de Berto et al. (2018) para BS foram inferiores a todas as variedades de feijão analisados. Resultados próximos ao analisado na variedade de feijão-caupi, foram observados por Tavares et al. (2015) ao avaliarem a qualidade de sementes armazenadas de feijão-azuki [Vigna angularis (Willd.) Ohwi \& H. Ohashi] em plântulas de sementes não armazenadas. 
Entre as variedades de feijão, o feijão-caupi foi que apresentou diferença entre todas as variedades e maior valor de CE $\left(229,56 \mu \mathrm{S} \mathrm{cm}^{-1} \mathrm{~g}^{-1}\right)$ indicando menor vigor entre as variedades analisadas. Em sentido oposto, as variedades de feijão comercial e feijão-fava mostraram-se mais vigorosas, com menor valor de CE $\left(0,16\right.$ e $0,08 \mu \mathrm{S} \mathrm{cm}^{-1} \mathrm{~g}^{-1}$, respectivamente). Considerando os resultados de CE para o feijão-caupi, observou-se que o vigor das sementes de feijão-caupi analisadas por Pinho \& Cunha (2019) foi superior, tendo em vista que o valor de CE foi muito inferior ao observado no presente trabalho.

Em seu estudo sobre os testes de vigor na avaliação da qualidade fisiológica de sementes de feijoeiro, Amaro et al. (2015) observou que o vigor dos lotes comerciais de feijão foi inferior ao analisado para o feijão comercial no presente trabalho. Além do vigor elevado do feijão comercial para a CE, o feijão-fava, apesar de ter apresentado vigor inferior para os demais parâmetros, demonstrou menor resultado de CE entre todas as variedades $\left(0,08 \mu \mathrm{S} \mathrm{cm}^{-1} \mathrm{~g}^{-1}\right)$ e, portanto, mostrou-se promissor com maior vigor apresentado entre os lotes de sementes. Nascimento (2020) ao estudar os aspectos genéticos e a qualidade fisiológica de sementes crioulas de feijão-fava encontrou resultados muito próximos para as variedades: Branca $\left(0,06 \mu \mathrm{S} \mathrm{cm}^{-1} \mathrm{~g}^{-1}\right)$, Orelha de Vó $\left(0,06 \mu \mathrm{S} \mathrm{cm}^{-1} \mathrm{~g}^{-1}\right)$, Raio de Sol $\left(0,05 \mu \mathrm{S} \mathrm{cm}^{-1} \mathrm{~g}^{-1}\right)$ e Cavalinha $\left(0,13 \mu \mathrm{S} \mathrm{cm} \mathrm{g}^{-1}\right)$.

\section{Conclusão}

As sementes de modo geral não mostraram-se tão promissoras, tendo sua qualidade muito abaixo do que se esperava, no entanto, a variedade crioula de milho urbano se destacou dentre as demais, demonstrando-se com qualidade levemente superior, superando inclusive a variedade testemunha (milho comercial); a variedade crioula de feijão-caupi se destacou, mas ainda assim o resultado foi inferior ao encontrado para a variedade de feijão comercial (testemunha) demonstrando qualidade fisiológica inferior. Por fim, para trabalhos subsequentes, sugere-se a realização das análises em lotes maiores de sementes, assim como a utilização de mais variedades testemunhas (comerciais) e realização de outros testes físicos e fisiológicos para fins de comparação dos resultados. E observações acerca das condições de armazenamento das sementes, e abordagens em regiões do sudeste e centro-oeste sobre essa temática.

\section{Referências}

ABRASEM. (2013). Instrução Normativa $n^{\circ} 45$, de 17 de setembro de 2013. http://www.abrasem.com.br/wp-content/uploads/2012/10/Instru\%C3 $\%$ A7\% $3 \%$ A3o-Normativa-n\%C2\%BA-45-de-17-de-Setembro-de-2013-Padr\%C3\%B5es-de-Identidade-e-Qualiidade-Prod-e-Comerc-de-Sementes-GrandesCulturas-Republica\%C3\%A7\%C3\%A3o-DOU-20.09.13.pdf.

Advíncula, T. L., Nadai, F. B., Costa Nobre, D. A., Ferreira, B., Moller, É. N., Brandão Júnior, D. S. \& Costa, C. A. (2015). Qualidade física e fisiológica de sementes de Phaseolus lunatus L. Revista Brasileira de Ciências Agrárias, 10 (3), 341-346.

Almeida, C. S., Guariz, H. R., Pinto, M. A. B. \& Almeida, M. F. (2020). Germination Of Creole Maize And Fava Bean Seeds Under Salt Stress. Rev. Caatinga [online], 33 (3), 853-859.

Amaro, H. T. R., David, A. M. S. S., Assis, M. O., Rodrigues, B. R. A., Cangussú, L. V. S. \& Oliveira, M. B. (2015). Testes de vigor para avaliação da qualidade fisiológica de sementes de feijoeiro. Revista de Ciências Agrárias, 38 (3), 383-389.

Batista, N. A. S., Luz, P. B., Sobrinho, S. P., Neves, L. G. \& Krause, W. (2012). Avaliação da qualidade fisiológica de sementes de feijão-caupi pelo teste de condutividade elétrica. Revista Ceres, 59 (1), 550-554.

Berto, T. S., Crisostomo, N. M. S., Ramos, M. G. C., Silva, C. L., Costa, E. A., Junior, J. L. A. M., Melo, L. D. F. A. \& Neto, J. C. A. (2018). Qualidade Fisiológica De Sementes De Feijão Crioulo Proveniente De Diferentes Localidades. Ciência Agrícola, 16 (1), $13-17$.

BRASIL - Ministério da Agricultura, Pecuária e Abastecimento. (2009). Regras para análise de sementes. Mapa/ACS, 15-398.

Bueno, J. J. T. (2020). Qualidade De Sementes De Cultivares De Feijão Comum. Trabalho de conclusão de curso (Agronomia) - Instituto Federal Goiano, Campus Ceres, 1-34.

Chagas, J. T. B., Farias, J. E. C., Souza, R. F., Freitas Júnior, S. P. \& Costa, M. G. S. (2018). Germinação E Vigor De Sementes Crioulas De Feijão-Caupi. Agrarian Academy, Centro Científico Conhecer - Goiânia, 5 (9), 487-498.

Coelho, S. V. B., Figueiredo, M. A., Clemente, A. C. S., Coelho, L. F. S. \& Rosa, S. D. V. F. (2015). Alterações fisiológicas e bioquímicas em sementes de café secas em sílica gel e soluções salinas saturadas. Pesquisa Agropecuária Brasileira, 50 (6), 483-491.

CONAB. (2020). Safra Brasileira de Grãos. https://www.conab.gov.br/info-agro/safras/graos 
CONAB. (2021). Safra Brasileira de Grãos. https://www.conab.gov.br/info-agro/safras/graos

Costa, R. Q., Moreira, G. L. P., Soares, M. R. S., Vasconcelos, R. C. \& Morais, O. M. (2013). Qualidade Fisiológica De Sementes De Milho Crioulo E Comerciais Semeadas Na Região Sudoeste Da Bahia. Enciclopédia Biosfera, Centro Científico Conhecer - Goiânia, 9 (16), 1873 -1880.

Crisostomo, N. M. S., Costa, E. A., Silva, C. L., Berto, T. S., Ramos, M. G. C., Junior, J. L. A. M., Melo, L. D. F. \& Neto, J. C. A. (2018). Qualidade fisiológica de sementes de milho crioulo proveniente de diferentes localidades. Revista Craibeiras de Agroecologia, 3 (1), e6555.

Derre, L. O., Daltoé, J. A., Sarubo, V. \& Abrantes, F. L. (2017). Influência Do Tamanho De Sementes Na Germinação E Vigor Inicial Da SojA (Glycine max). Colloquium Agrariae, 13 (1), 100-107.

Feitosa, B. E. S., Corrêa, M. L. P., Félix, J. P. S. \& Silva, P. B. (2018). Sanidade e germinação de sementes de variedades crioulas de milho armazenadas por agricultores familiares no município de Belterra-Pará. Cadernos de Agroecologia, 13 (1), 1-5.

Ferreira, D. F. (2011). Sisvar: A computer statistical analysis system. Ciência e Agrotecnologia, 35 (6), 1039-1042.

Firmino, C. W. S. R. (2017). Emergência E Vigor De Cultivares De Feijão-Caupi. Trabalho de conclusão de curso (Agronomia) - Universidade Federal Rural do Semi-Árido, CCA, Departamento de Ciências Agronômicas e Florestais, Mossoró, 1-28.

Franzin, S. M., Menezes, N. L., Garcia, D. C. \& Wrasse, C. F. (2004). Métodos para avaliação do potencial fisiológico de sementes de alface. Revista Brasileira de Sementes, 26, 63-69.

Garcindo, L. (2009). O Cultivo De Sementes Crioulas No Sudeste Goiano: Uma Forma Da (Re)Existência Camponesa No Campo. UFG/Campus Catalão. Artigo apresentado no: XIX Encontro Nacional De Geografia Agrária, 1-17.

Gondim, T. C. O., Rocha, V. S., Santos, M. M. \& Miranda, G. V. (2006). Avaliação da qualidade fisiológica de sementes de milho-crioulo sob estresse causado por baixo nível de nitrogênio. Revista Ceres, 53 (307), 4013-417.

Guedes, S. R., Alves, E. U., Santos-Moura, S. S. \& Galindo, E. A. (2015). Teste de comprimento de plântula na avaliação da qualidade ¿siológica de sementes de Amburana cearensis (Allemão) A.C. Smith. Semina: Ciências Agrárias, 36 (4), 2373-2382.

IBGE. (2020). Levantamento Sistemático da Produção Agrícola. https://sidra.ibge.gov.br/tabela/1618

Limão, M. A. R. (2019). Caracterização Da Qualidade De Sementes De Variedades Crioulas De Milho (Zea mays L.). Trabalho de conclusão de curso (Agronomia) - Universidade Federal de Campina Grande (CCTA), 1-63.

Londres, F. (2014). As sementes da paixão e as políticas de distribuição de sementes na Paraíba. AS-PTA, 83 p.

Ludwig, M. P., Lucca Filho, O. A., Baudet, L., Dutra, L. M. C., Avelar, S. A. G. \& Crizel, R. L. (2011). Qualidade De Sementes De Soja Armazenadas Após Recobrimento Com Aminoácido, Polímero, Fungicida E Inseticida. Revista Brasileira de Sementes, 33 (3), $395-406$.

Maguire, J. D. (1962). Speed of germination-aid selection and evaluation for seedling emergence and vigor. Crop Science, 2 , $176-177$.

Maia, A. F., Assunção, M. V. \& Alves, J. F. (1986). Influência do método de debulha e da umidade na produção de sementes de feijão de corda. Ciência Agronômica, 17 (2), 91-100.

Marcos Filho, J. (1999). Testes de vigor: importância e utilização. In: Krzyzanowski, F. C., Vieira, R. D. \& França Neto, J. B. (Eds.). Vigor de sementes: conceitos e testes. Londrina: ABRATES. $21 \mathrm{p}$.

Menezes, A. C. P., Jesus, R. M., Santos, E. N., Didolanvi, O. D. \& Santana, C. V. S. (2020). Potencial fisiológico de sementes de milho armazenadas por pequenos agricultores no município de Euclides da Cunha/BA. Cadernos de Agroecologia - Anais do XI Congresso Brasileiro de Agroecologia, 15 (2), 1-5.

Miranda, G. V., Caniato, F. F., Fidelis, R. R., Araújo, E. F., Souza, L. V. \& Doná, A. A. (2003). Qualidade fisiológica de sementes de populações de milho crioulo da zona da mata de Minas Gerais. Revista Ceres, 50 (289), 337-345.

Nakagawa, J. (1999). Testes de vigor baseado no desempenho de plântulas. In: Kryzanowski, F. C., Vieira, R. D. \& França Neto, J. B. (ed.). Vigor de sementes: conceitos e testes. Londrina: Abrates. cap. 2, 1-2.

Nascimento, M. G. R. (2020). Aspectos Genéticos E Qualidade Fisiológica De Sementes Crioulas De Phaseolus lunatus L. Tese (Doutorado em Agronomia) Universidade Federal da Paraíba, CCA, PPGA, 1-135.

Oliveira, F. N., Torres, S. B. \& Bebedito, C. P. (2011). Caracterização Botânica E Agronômica De Acessos De Feijão-Fava, Em Mossoró, RN. Revista Caatinga, 24 (1), 143-148.

Padua, G. P., Zito, R. K., Arantes, N. E. \& França Neto, J. B. (2010). Influência do tamanho da semente na qualidade fisiológica e na produtividade da cultura da soja. Revista Brasileira de Sementes, 32 (3), 9-16.

Pereira, A. P. (2020). Caracterização De Sementes Crioulas Do Alto Sertão Sergipano. Trabalho de Conclusão de Curso (Engenharia Agronômica) Universidade Federal de Sergipe, 1-54.

Pinho, A. C. \& Cunha, P. S. J. (2019). Avaliação Da Qualidade Fisiológica De Sementes De Feijão-Caupi (Vigna unguiculata (L.) Walp.). Trabalho de conclusão de curso (Agronomia) - Universidade Federal Rural da Amazônia, 1-36.

Queiroz, T. N., Valiguzski, A. L., Braga, C. S., Souza, S. A. M. \& Rocha, A. M. (2019). Avaliação da qualidade fisiológica de sementes de variedades tradicionais de milho. Revista da Universidade Vale do Rio Verde, 17 (1). 
Ramos, K. M. O., Felfili, J. M., Faggi, C. W., Souza-Silva, J. C. \& Franco, A. C. (2004). Crescimento inicial e repartição da biomassa de Amburana cearensis (Allemao) A. C. Smith. Em diferentes condições de sombreamento. Acta Botânica Brasílica, 1 (18), 351 - 358.

Rocha, G. P., Silva, N. C., Dourado, E. R., Teixeira, M. S., Junior, D. B. \& Bramdão, G. S. (2009). Qualidade fisiológica de sementes de milho (Zea mays) e Sorgo (Sorghum bicolor) crioulos produzidas nos campos de sementes de agricultores (as) familiares de Porteirinha, Norte de Minas Gerais. Revista Brasileira de Agroecologia, 4 (2).

Rosa, C. C. (2020). Qualidade Fisiológica De Sementes De Milho Submetidas A Tratamento Químico E Bioestimulantes. Dissertação (Mestrado Em Agronomia), Universidade De Brasília, 1-54

Sa, M. E., Oliveira, S. A. \& Bertolin, D. C. (2011). Roteiro Prático Da Disciplina De Produção E Tecnologia De Sementes: análise da qualidade de sementes. São Paulo: Cultura Acadêmica. 112 p.

Santos, J. A. (2015). Avaliação Da Qualidade Física E Fisiológica De Sementes De Milho Adubado Com Resíduos Avícolas. Dissertação (Mestrado em Fitotecnia) - Universidade Federal de Viçosa, PPGF, 1-67.

Santos, M. P., Vale, L. S. R., Reges, N. P. R. \& Carvalho, B. M. (2015). Desempenho De Sementes De Quatro Cultivares De Feijão (Phaseolus vulgaris L.) Na Microregião De CERES - GO. Global Science and Technology, 8 (3), 41-49.

Schafranski, B. P., Morais, G. I. \& Carvalho, T. C. de. (2019). Efeito do estresse salino em sementes de feijão dos grupos comerciais carioca e preto. Applied Research \& Agrotechnology, 12 (3), 17-30.

Sena, D. V. A., Alves, E. U. \& Medeiros, D. S. (2015). Vigor tests to evaluate yhe physiological quality of corn seeds cv. "Sertanejo". Ciência Rural, 47 (3), $1-7$.

Silva, A. L., Silva, J. F., Almeida, F. A. C., Gomes, J. P., Alves, N. M. C. \& Araujo, D. R. (2012). Qualidade fisiológica e controle de sementes de milho tratadas com Piper nigrum. Revista Brasileira de Produtos Agroindustriais, 14, 131-142.

Silva, F. A., Silva, J. R. A., Meireles, D. A., Fraga, V. S. \& Oliveira, M. R. T. (2016). Características Tecnológicas De Variedades De Feijão Macassar Cultivados Em Região Semiárida Paraibana. Anais I CONIDIS... https://www.editorarealize.com.br/index.php/artigo/visualizar/23608

Silva, F. H. A., Nascimento, S. R. C., Torres, S. B., Oliveira, J. R., Alves, T. R. C. \& Negreiros, A. M. P. (2019). Qualidade sanitária de sementes salvas de feijão-caupi utilizadas pelos agricultores do Rio Grande Norte. Revista de Ciências Agrárias - Amazonian Journal of Agricultural and Environmental Sciences, 59 (1), 60-65.

Silva, F. S., Porto, A. G., PascualI, L. C. \& Silva, S. T. C. (2010). Viabilidade do armazenamento de sementes em diferentes embalagens para pequenas propriedades rurais. Revista de Ciências Agro-Ambientais, 8 (1), 45- 56.

Silva, K. C. N. (2020). Avaliação Do Vigor De Sementes Crioulas De Milho (Zea mays L.) Utilizando Testes Tradicionais E Análise De IMAGENS. Dissertação (Mestrado em Ambiente, Tecnologia e Sociedade) - Universidade Federal Rural do Semi-Árido (PPGATS), 1-53.

Silva, R. T. (2017). Qualidade fisiológica de sementes crioulas de Fabaceae. Trabalho de Conclusão de Curso (Agronomia) - Universidade Federal da Paraíba (CCA/UFPB), 1-45.

Silva, G. C., Gomes, D. P., Kronka, A. Z. \& Moraes, M. H. (2008). Qualidade fisiológica e sanitária de sementes de feijoeiro (Phaseolus vulgaris L.) provenientes do estado de Goiás. Semina: Ciências Agrárias, 29 (1), 29-34.

Silveira, M. A. M., Villela, F. A. \& Tillmann, M. A. A. (2002). Comparação de métodos para avaliação da qualidade fisiológica em sementes de calêndula. Revista Brasileira de Sementes, 24 (2), 24-30.

Tavares, C. J., Araújo, A. C. F., Jakelaitis, A., Resende, O., Sales, J. F. \& Freitas, M. A. M. (2015). Qualidade de sementes de feijão-azuki dessecadas com saflufenacil e submetidas ao armazenamento. Revista Brasileira de Engenharia Agrícola e Ambiental, 19 (12), $1197-1202$.

Vazquez, G. H., Arf, O., Sargi, B. A. \& Pessoa, A. C. O. (2012). Influência do tamanho e da forma da semente de milho sobre o desenvolvimento da planta e a produtividade da planta e a produtividade de grãos. Bioscience Journal, 28 (1), 16-24.

Vieira, R. D. \& Krzyzanowski, F. C. (1999). Teste de condutividade elétrica. In: Krzyzanowski, F. C., Vieira, R. D. \& França Neto, J. B. (Ed.). Vigor de sementes: conceitos e testes. ABRATES, 1-26. 